\title{
Korelasi Skor Lund-Mackay dan Volume Cairan Sinus Berdasarkan Gambaran CT-Scan Sinus Paranasalis 3D dengan Skor SNOT-22 pada Pasien RSK Tanpa dan dengan Polip
}

\section{Correlation between Lund-Mackay Scores and Sinus Fluid Volume Based on 3D CT Paranasal Sinus Scan with SNOT-22 Score in Patients with Chronic Rhinosinusitis with and Without Polyps}

\author{
Muhammad Ridha Maulana ${ }^{1}$, Nurlaily Idris ${ }^{2}$, Nikmatia Latief $^{2}$, \\ Burhanuddin Bahar ${ }^{3}$, Muhammad Fadjar Perkasa ${ }^{4}$, Muhammad Ilyas ${ }^{2}$ \\ ${ }^{I}$ Resident, Department of Radiology, Faculty of Medicine, Hasanuddin University, Makassar \\ ${ }^{2}$ Department of Radiology, Faculty of Medicine, Hasanuddin University, Makassar \\ ${ }^{3}$ Department of Public Health Science, Faculty of Medicine, Hasanuddin University, Makassar \\ ${ }^{4}$ Department of ENT-KL Health Sciences, Faculty of Medicine, Hasanuddin University, Makassar \\ E-mail: mridhamaulana@gmail.com
}

KEYWORDS Lund-Mackay, SNOT-22 score, chronic rhinosinusitis, paranasal sinus CT scan

ABSTRACT The aim of this study is to determine the correlation between Lund-Mackay scores and sinus fluid volume based on 3D CT paranasal sinus scan with SNOT-22 score in patients with chronic rhinosinusitis without and with polyps. This research was conducted at the Department of Radiology Hasanuddin University Hospital Makassar from April to June 2019. Samples were 38 patients without and with polyps in age $\geq 18$ years. The method used is the Spearman rho test. The results showed a correlation between sinus fluid volume and SNOT-22 score in patients with chronic rhinosinusitis without polyps $n=25, p=0.042$ ( $p<0.05)$, the higher the sinus fluid volume, means the SNOT-22 score was higher in patients with chronic rhinosinusitis without polyps. There was no correlation between sinus fluid volume and SNOT-22 score in patients with chronic rhinosinusitis with polyps $n=13, p=0.077$ ( $p<0.05$ ), there was not any correlation between Lund-Mackay scores and SNOT-22 scores in patients with chronic rhinosinusitis without and with polyps.

\section{PENDAHULUAN}

Rinosinusitis merupakan masalah kesehatan dengan angka insidensi tergolong tinggi setiap tahunnya. Tahun 1996 survey kesehatan Amerika mencatat RSK menduduki peringkat kedua penyakit kronis dengan insiden $12,5 \%$ dari penduduk atau 31 juta penderita setiap tahunnya (Hamilos, 2011).

Pada tahun 2008, tercatat 1 dari 7 dewasa menderita RSK sedang tahun 2009 dari hasil survei kesehatan di Amerika Serikat menyatakan 29,3 juta 
orang dewasa didiagnosis dengan rinosinusitis, atau sekitar $12,6 \%$ dari populasi masyarakat Amerika Serikat. Prevalensi pada wanita dilaporkan sebanyak 20,9\%, hampir dua kali lipat dibandingkan pada pria $(11,6 \%)$. (Hoddeson et al., 2014 dan Fokken et al., 2012). Pada tahun 2003, survey DEPKES RI menyatakan bahwa RSK berada pada urutan ke-25 dari 50 pola penyakit tingkat utama (Multazar et al., 2012).

Mekanisme patologik utama dan terpenting pada rinosinusitis kronik (RSK) adalah obstruksi ostium sinus. Berbagai faktor lokal maupun sistemik dapat menyebabkan inflamasi atau kondisi yang mengarah pada obstruksi ostium sinus (Brook, 2006 dan Kentjono, 2004).

Polip nasi timbul dari setiap bagian mukosa hidung atau sinus paranasal sebagai hasil akhir dari berbagai proses penyakit sinonasal. Polip mukosa yang paling umum adalah lesi inflamasi rongga hidung jinak yang muncul dari mukosa rongga hidung atau sinus paranasal sering pada saluran keluar dari sinus. Ini memiliki etiologi inflamasi, tetapi mekanisme pastinya tidak pasti (Anthony, 2011). Pengamatan dari hasil CT scan, polip adalah lesi jaringan lunak atau padat cairan dengan sekresi kering lebih banyak yang terperangkap di antara multiple polip. Ini menghasilkan pola yang halus namun khas pada sinus maksilaris, sehingga tampak kerapatan lengkung yang mengalir turun dari ostium sinus (Gitta et al., 2009).

Dari berbagai sistem yang telah dikembangkan, skor Lund-Mackay (LMS) telah terbukti menjadi metode penilaian yang efektif dan alat penelitian pencitraan yang mudah digunakan dalam prakteknya (Weisberg et al., 2009).
Skor berdasarkan penemuan CTscan pada setiap sinus dan di setiap bagian kanan dan kiri kemudian diberi skor nomor : $0=$ tidak ada kelainan, $1=$ perselubungan parsial, dan $2=$ perselubungan total. Sedang untuk KOM kanan dan kiri diberi skor nomor $0=$ tidak ada obstruksi dan 2= obstruksi, sehingga skor total kemungkinan adalah 24 (Aygun, 2005, Zeifer \& Curtin, 2006, Soetjipto et al,2006).

Untuk mengukur volume perselubungan sinusitis digunakan CT scan 3D dengan irisan $3 \mathrm{~mm}$ potongan aksial dan dinilai dengan komputer workstation (Jonathan garneau et al., 2015). Software secara otomatis menghitung daerah yang diinginkan, software telah dikembangkan untuk menilai mukosa secara tiga-dimensi (3D), analisis volumetric, analisis gambar telah digunakan diberbagai bidang otolaringologi, termasuk penyakit sinus (Garneau et al., 2015).

Penilaian anamnesis bisa dilakukan dengan menggunakan kuisioner yang telah diakui valid untuk pemeriksaan sino-nasal yaitu SNOT-22. SNOT-22 merupakan modifikasi kuisioner SNOT-20, kuisioner SNOT-22 terdiri dari 22 poin pernyataan dengan 6 tingkat penilaian. Diantara 22 pernyataan tersebut 12 poin mencakup gejala fisik pasien, 10 poin lainnya mencakup kualitas hidup pasien (Lachanas et al., 2014, dan Poirrier et al., 2013).

Berdasarkan hal diatas, maka penelitian untuk mengetahui hubungan antara skor Lund-Mackay dan volume cairan sinus berdasarkan CT-scan sinus paranasalis 3D dengan SNOT-22 pada penderita RSK tanpa dan dengan polip di Rumah Sakit Pendidikan Universitas Hasanuddin Makassar. 


\section{METODOLOGI}

Jenis penelitian ini merupakan studi diagnostik yang bersifat analitik observasional. Populasi penelitian seluruh pasien yang diagnosis menderita rhonosinusitis kronis yang datang ke bagian radiologi RSUP. Hasanuddin serta akan melakukan pemeriksaan CT scan sinus paranasalis 3D dengan kriteria usia $\geq 18$ tahun, dapat mengikuti dan memahami instruksi pengisian kuisioner SNOT-22, tidak menderita tumor sinonasal, tidak pernah menjalani operasi BSEF sebelumnya, dan bersedia menjadi sampel. Jumlah yang memenuhi kriteria sebanyak 38 sampel. Pengambilan data dilakukan dalam rentang waktu Mei 2019 sampai dengan Juli 2019 dengan teknik pengambilan sampel secara consecutive sampling, yaitu semua penderita RSK tanpa dan dengan polip yang memenuhi kriteria (Notoatmodjo, 2005).

Instrumen yang digunakan adalah CT scan 3D merek SIEMENS High Speed dual source menggunakan sistem software (ABRAS). ABRAS merupakan alat visualisasi dan manipulasi gambar yang memungkinkan penyesuaian window, pembesaran, dan visualisasi untuk semua bagian dari CT scan. Semua rongga sinus diuraikan secara manual di sepanjang landmark tulang yang menentukan sinus (tidak termasuk KOM) di setiap gambar bagian CT. instrumen lainnya adalah kuisioner yang telah diakui valid untuk pemeriksaan sinonasal yaitu SNOT-22, alat tulis, dan format pengumpulan data untuk mendata hasil pemeriksaan $\mathrm{CT}$ scan 3D yang dilakukan oleh konsulen radiologi

Data dianalisis dengan uji bivariate untuk mengetahui hubungan antara skor Lund-Mackay dengan skor SNOT-22 pada pasien RSKRSK tanpa dan dengan polip, dan hubungan antara volume cairan sinus dengan skor SNOT22 pada pasien RSK tanpa dan dengan polip dengan uji Spearman's Rho (Dahlan, 2013).

\section{ISI}

Dari hasil peneltian, distribusi jenis kelamin pasien RSK tanpa dan dengan polip diketahui jumlah pasien berjenis kelamin perempuan sebanyak 24 orang (63.2\%), dan jumlah pasien berjenis kelamin laki-laki sebanyak 14 orang (36\%). Bila ditinjau dari distribusi kelompok umur rhinositinusitis kronis tanpa dan dengan polip diketahui kelompok umur 17-25 tahun berjumlah 10 orang $(26.3 \%)$, kelompok umur $26-35$ tahun berjumlah 12 orang (31.6\%), kelompok umur 36-45 tahun berjumlah 9 orang (23.7\%), kelompok umur 46-55 tahun berjumlah 3 orang, kelompok umur 56-65 tahun berjumlah 2 orang (5.3\%), kelompok umur $>65$ tahun berjumlah 2 orang (5.3\%).

Hasil uji korelasi skor LundMackay dan volume cairan sinus dengan skor SNOT-22 pada pasien RSK tanpa dan dengan polip dapat dilihat pada Tabel 1. 
Tabel 1. Korelasi volume cairan sinus, skor Lund-Mackay, skor SNOT-22 pada pasien RSK tanpa dan dengan polip

\begin{tabular}{|c|c|c|c|c|c|c|c|}
\hline & \multirow{3}{*}{$\mathrm{n}$ (total) } & \multicolumn{6}{|c|}{ Skor SNOT-22 } \\
\hline & & \multicolumn{3}{|c|}{ Tanpa polip } & \multicolumn{3}{|c|}{ Polip } \\
\hline & & $\mathrm{n}$ & $\mathrm{r}$ & $\mathrm{p}$ & $\mathrm{n}$ & $\mathrm{r}$ & $\mathrm{p}$ \\
\hline Volume cairan sinus & 38 & 25 & 0.409 & 0.042 & 13 & 0.507 & 0.077 \\
\hline Skor Lund-Mackay & 38 & 25 & 0.331 & 0.106 & 13 & 0.255 & 0.401 \\
\hline
\end{tabular}

Keterangan : $n:$ jumlah, $r:$ kekuatan korelasi, $p:$ korelasi $<0.05$, uji Spearman's rho

Sumber : data primer

Uji analisis memperlihatkan korelasi cairan sinus, skor Lund-Mackay, Skor SNOT-22 pada pasien RSK tanpa dan dengan polip pada 38 sampel menggunakan uji Spearman's rho dengan $\mathrm{p}<0.05$ dimana korelasi sedang antara volume cairan sinus dengan skor SNOT22 pada pasien rhinosinusitis tanpa polip n (25), r (0.409), p (0.042), tidak terdapat korelasi antara volume cairan sinus dengan skor SNOT-22 pada pasien rhinosinusitis dengan polip $\mathrm{n}$ (13), $\mathrm{r}$ (0.507), p (0.077), tidak terdapat korelasi antara skor Lund-Mackay dengan skor SNOT-22 pada pasien RSK tanpa polip n (25), r (0.331), p (0.106), tidak terdapat korelasi antara skor Lund-Mackay dengan skor SNOT-22 pada pasien RSK dengan polip $\mathrm{n}$ (13), $\mathrm{r}(0.255), \mathrm{p}(0.401)$.

Hasil penelitian ini sesuai dengan penelitian yang dilakukan oleh Sooyong Lim, et all, (Lim et al., 2017) pada pasien dewasa ( $\geq 18$ tahun) yang menderita sinusitis dan dilakukan pemeriksaan CT scan 3D didapatkan korelasi volume inflamasi pada sinus dengan analisa 3D dengan skor SNOT-22, sedangkan antara volume cairan sinus dengan skor SNOT22 pada pasien RSK dengan polip tidak ada korelasi dimana n (13), r (0.507), p (0.077), hasil ini juga sesuai dengan penelitian yang dilakukan oleh Marc Garetier et al. (2013) tidak terdapat korelasi antara volume sinusitis pada CT scan sinus paranalis 3D dengan skor SNOT-22.

Uji Sperman's rho memperlihatkan tidak ada korelasi antara skor Lund-Mackay dengan skor SNOT22 pada pasien RSK tanpa dan dengan polip dimana n (25), p (0.331), r (0.106) pada rhinosinusitis tanpa polip dan $\mathrm{n}$ (0.255), r (0.255), dan $\mathrm{p}$ (0.401) pada rhinosinusitis dengan polip, hasil ini sesuai dengan penelitian yang dilakukan oleh S. Basu, et al, (Georgalas \& Desai, 2005) pada sampel yang terkena RSK dimana tidak terdapat korelasi antara skor SNOT-22 dengan skor Lund-Mackay. Peneliti lainnya, Tomislav Gregurić membuktikan hal yang sama pada 271 sampel RSK dimana tidak terdapat korelasi antara skor SNOT-22 dengan skor Lund-Mackay.

\section{PENUTUP}

Terdapat korelasi sedang antara volume cairan sinus dengan skor SNOT22 pada pasien RSK tanpa polip.Tidak tedapat korelasi antara volume cairan sinus dengan skor SNOT-22 pada pasien RSK dengan polip dan tidak terdapat korelasi antara skor Lund-Mackay dengan skor SNOT-22 pada pasien RSK tanpa dan dengan polip. 


\section{DAFTAR PUSTAKA}

Anthony, A., Mancuso, William O., Collins, Carol, J. Langdoc: 2011. Chronic Sinusitis and Nasal Polyposis. Head and Neck Radiology. Vol I. Philadelphia, PA 19103

Aygun, N. 2005. Radiology of Nasal Cavity and Paranasalis Sinuses. Cummings Otolaryngology Head and Neck Surgery 4th ed. Vol 2. Elsevier Mosby Philadelphia. p; 1153-6.

Brook, I. 2006. Infectious Causes of Sinusitis in Sinusitis from Microbiology to Management edited by Itzhak Brook, Georgetown University School of Medicine Washington, D.C., U.S.A.New York. p: 154

Dahlan, M.S. 2013. Statistik Untuk Kedokteran dan kesehatan. Salemba Medika. 175-178.

Fokkens, W.J., Lund, V.J., Mullol, J., Bachert, C., Alobid, I. 2012. Chronic Rhinosinusitis with or without Nasal Polyps. Eur Position Pap Rhinosinusitis Nasal Polyps. 50 Suppl 23:55-110.

Garetier, M. et al. 2013. Clinicalradiological correlation after functional endoscopic sinus surgery in patients with chronic rhinosinusitis : interest of a sinonasal aerial volumetry. (3): 162-170. doi: 10.4193/ Rhino12.131.

Garneau, J., Samuel, G., Armato, I, et al. 2015 July. Computer-Assisted Staging of Chronic Rhinosinusitis Correlates with Symptoms. Int Forum Allergy Rhinol. 5(7): 637642. doi:10.1002/alr.21499.

Georgalas, S.B.C., Desai, S. 2005.
Correlation between symptoms and radiological findings in patients with chronic rhinosinusitis: an evaluation study using the Sinonasal Assessment Question naire and Lund-Mackay grading system. 751-754. doi: 10.1007/ s00405-004-0891-0.

Gitta, M., Beale, T.J. 2009. Sinonasal Inflammatory Disease. University College Hospital London, London, UK.doi:10.1053/j.sult.2008.10.012.

Hamilos, D.L. 2011. Chronic rhinosinusitis: Epidemiology and medical management. Journal of Allergy and Clinical Immunology. Elsevier Ltd, 128(4), pp. 693-707. doi: 0.1016/j.jaci.2011.08.004.

Hoddeson, E., Wise, S. Acute Rhinosinusitis. In: Johnson J, Rosen C, editors. 2014. Bailey's Head and Neck Surgery Otolaryngology. fifth. Philadelphia: Lippincot. 509-14.

Kentjono, W.A. 2004. Rinosinusitis: Etiologi dan Patofisiologi dalam Naskah Lengkap Perkembangan Terkini Diagnosis dan Penatalaksanaan Rinosinusitis, Bagian Ilmu Kesehatan THT FK Unair/RSU Dr. Soetomo, Surabaya. 1-16.

Lachanas, V., Tsea, M., Tsiovaka, S., Hajiioannou, J., Skoulakis, C., Bizakis, J. 2014. The Sino-nasal Outcome Test (SNOT)-22: Validation for Greek Patients. Eur Acrh Otorhinolaryngol.1-6.

Multazar, A., Nursiah, S., Rambe, A., Harahap, I.S. 2012. Eksprsi Cyclooxygenase-2 (COX-2) pada Penderita Rinosinusitis Kronis. Oto Rhino Laryngol Indonesia.42(2):96-103. 
Notoatmodjo, S. 2005. Metodologi Penelitian Kesehatan. Rineka Cipta. Jakarta. 138-144.

Poirrier, A., Ahluwalia, S., Goodson, A., Ellis, M., Bentley, M., Andrews, P. 2013. Is the Sino-Nasal Outcome Test-22 a Suitable Evaluation for Septorhinoplasty? Laryngoscope. 123:76-81.

Soetjipto, D., Dharmabakti, U., Mangunkusumo, E., Utama, R,. dkk. 2006. Functional Endoscopic
Sinus Surgery di Indonesia pada Panel Ahli THT Indoneaia. p:1-52. Weisberg, L.A. 1984. Cerebral Computed Tomography A Text Atlas. Second Edition. W. B. Saunders Company. Philadelphia, London.

Zeifer, B.A., Curtin, H.D. 2006. Sinus Imaging in Byron J Bailey \& Jonas T Johnson, Head and Neck Surgery Otolaryngology, 4th ed,Vol 1,Lippincott Williams \& Wilkins, Philadelphia,USA. p: 429-45. 